appeared to them to have at bottom no value. In their inmost heart they always guarded the firm persuasion that liberty alone is able to remedy the abuses of liberty, and that a more mature science. would rectify the errors of an incomplete science. The sentiment which urged them to shake off the yoke of the Roman Church is also that under the sway of which the German universities have been organised.

But every institution founded on liberty is obliged to count on the intelligence and judgment of those who use the liberty. Independently of what has been said above on the strbject of the decisions which the students have to take for themselves in what concerns the direction of their studies. and the choice of their masters, the reflections which precede show also the influcnce which they may exercise on the masters themselves. It is a difficult thing to have to continue the course commenced by a colleague, and that difficulty is presented at the ontset of every semester. At every moment the progress of the coure obliges us to fall back upon what has been previously said, to consider the same questions from other points of view and in another order. The master would soon tire of this ungrateful task, if he did not find support in the zeal of his audience. In order to be at the height of his mission, he must feel himself sustained and understood by a sufficient number of intelligent pupils. The flocking of an audience to the lessons of a master has no little influence on his nomination or his advancement; and it has an influence also upon the whole of the teaching body. All this system rests upon the idea that the general current of the opinion of the students cannot long be at fault. The majority among them come to us with a reason sufficiently formed by logic, with a sufficient habit of intellectual effort, witi a judgment so considerably developed by a knowledge of the best models, to be able to discern the truth from a phraseology which has only the appearance of truth. Among students we may already clistin. guish the slite who will be the intellectual guides, of the new generation, and who, in a few years, may perhaps attract the attention of the world. They are those who, especially, in scientific matters, determine the opinion of their comrades; the others involuntarily allow themselves to be guided by them. Naturally, young spirits, inexperienced and impressionable, are liable to fall tmomentarily into error; but, in short, we may be sure that they..will always return soon to just ideas.

Such are, at least, those whom the lyreums have sent to us hitherto. - It would be dangerous for the universities to see arriving in great numbers, students less cultivated. It is necessary that the general spirit of the students should not decline. If that happened, the dangers of academic liberty would surpass its advantages. We ought not then to accuse the univer sities of pride or pedantry, when they admit only with circum spection students educated outside the lycetums, It would be more dangerous still for a foreign pressure to introduce into the faculties masters who would not be fully qualified for having the scientific independence of an academic professor.

Do not forget, then, clear comrades, that you have a great responsibility. This glorious legacy of the past, of which I have already spoken, you have to preserve, not only for our own nation, but also to serve for example to a great portion of humanity. You are bound also to prove that youth is capable of enthusiasm for the independence of convictions and of working for it. I say working. In fact, the independence of convictions does not consist in lightly accepting hypotheses without proofs; it can only be the fruit of experiments and of persevering labours. It is your duty to show that the convic tions, founded on personal researches, are germs most fruitful of new ideas, and furnish better rules of conduct than the direction of the best-intentioned authority. Germany, who, in the sixteenth century was the first to strive for the liberty of convictions, who suffered and was martyred for them, is yet in the van of the fight. A noble mission is allotted to her in the history of the world, and you are called to contribute to its triumph.

\section{REMARKABLE CHANGES IN THE EARTH'S MAGNETISM ${ }^{1}$}

ONE of the most important, scientifically, of the special lectures at the Geographical Society, was that by Capt. Evans, in March last, on the strbject of terrestrial magnetim. The

1 From Lecture at the Royal Ge graphcal Sucety, March it, by Captain F J. Evans, C.B. F.R.S, Hydregraher to the Adnutralty. concluding portion, especially, is of high scientific importance. Capt. Evans gave a historical sketch of the subject of terrestrial magnetism from the time of the discovery of the dip of the magnetic needle. After speaking further on various depart: ments of his subject, Capt. Evans wert on to say :-

"We have now passed in review the successive stages of de velopment of our branch of knowledge, from the pregnant epoch when its principles were enunciated by Gilbert, till the period when the well-directed munificence of his own and other Governments dotted the earth's surface with observatories, and despatched land and sea expeditions, specially equiped, for the deterinination of the magnetic elements. We have seen how, a few earnest and gifted men have, by long and patient analyșis, laid the foundations for future generations to build upon as re gards theory, and unravelled the apparently inextricable web surrounding the needle's daily and yearly movements; tracing these movements to their primary source, the sun : and how by the perseverance of states and of individuals, we are now in possession of accurate knowledge as to the distribution of magnetism over the surface of our globe, as represented by the variation and dip of the needle, and by the measure of the force connected with those component elements. But the task, from a scientific point of view, is far from completed while we remain in ignorance of the causes of greater changes in the earth's magnetism going on from year to year, and so on, possibly through xons of time. From a practical point of view, so far as the interests of men are concerned, the collection of records will be a never ending task, for every generation must observe and chart the magnetic elements of its time.

"The subject of secular" change is thus one of such great interest that the remaining portion of my lecture must be chiefly devoted to it. The active mind of Halley, was drawn, as one of the first, to the probable nature of the causes : collecting such observations of the variation of the compass as had then been made, and projecting them on polar maps, he found that the convergence of the several directions of the needle led to two points in each hemisphere. On this he enunciated the proposi tion 'that the whole globe of the earth is one great magnet, having four magnetical poles or points of attraction; near each pole of the equator two ; and that in those parts of the world which-lie near adjacent to any of these magnetic poles the needle is governed thereby, the nearest pole always being predominant over the more remote' Halley saw, as he confessed with despair, the difficulties attending the proposition, 'as never having heard of a magnet having four poles,' but there were the facts manifested by the earth, and he was too sagacious and sound a philosopher to pass them by. He accordingly propounded a theory which, however fantastic it may now appear, and perhaps did at the time he wrote, has nevertheless within it the fire of genius, and may probably be found yet to contain some sparks of truth. To account for the four poles, and at the same time for the secular change of the variation, he conceived that the earth itself might be a shell, containing within a solid globe, or terella, which rotated independently of the external shell : each globe having its own magnetic axis passing through the common centre; but the two axes inclined to each other and to that of the earth's diurnal rotation. It is not difficult to follow the movements of the consequent four imaginary poles in solu. tion of the problem.

"Hansteen working at the same problem a century after Halley [I $11-19]$, and much on the same lines, came nearly to the same conclusion with regard to the four poles of attraction : and he rendered justice to Halley by recognising him as the first who had discovered the true magnetic attraction of the globe. Han. steen, with the material at his command, went however a step further, and computed both the geographical positions and the probable period of the revolution of this dual system of poles or points of attraction round the terrestrial pole. From these computations he found that the North American point or pole required $\mathbf{I}, 74^{\circ}$ years to complete its grand circle round the terrestrial pole, the Siberian 860 years; the pole in the Antarctic reyions south of Australia, 4,6co years; and a secondary pole near Cape IIorn, I, 304 years. ${ }^{1}$ The influence of these laborious investigations on the minds of subsequent inquirers may easily be imagined.

"The matured view's of Sir Edward Sabine on the secular changes-enunciated in the clearest manner in $1864-72$-are deserving of the highest consideration. An ardent admirer of 
the genius and no less of the sagacity of Halley, he in part follows Halley's views, and considers that two magnetic systems are directly recognisable in the phenomena of the magnetism of the globe; the one having a terrestrial, the other a cosmical origin. The magnetism proper of the globe, with its point of greatest attraction (i.e. in the northern hemisphere) in the north of the American continent is the stronger; the weaker system, or that which results from the magnetism induced in the earth by cosmcal action, with its point of greatest attraction is, at present, in the north of the Asiatic continent. Sir Edward Sabine also expresses his belief that 'it is the latter of these two systems which by its progressive translation, gives rise to the phenomena of secular change, and to those magnetical cycles which owe their origin to the operation of the secular change.'1

"Reviewing these several hypotheses by the light of observations made in recent years, it is difficult, and indeed in some directions, impossible to recognise their accordance with changes now going on: there can be no doubt, notwithstanding, that Halley and Hansteen analysed their facts with skill, and that their deductions were borne out by those facts. In explanation of this anomaly it is necessary to glance retrospectively on the changes in progress at the times in which these philosophers gave utterance to their views [1700-1819]. During this long interval, and, so far as relates to parts of the northern hemisphere, for a century before, there was in the higher latitudes a general movement of the north end of the needle in the following directions:-

"Over all that area (embracing the Atlantic and Indian Oceans) from Hudson's Bay to about the mexidian of the North Cape o Europe, and from Cape Horn to about the western part of Australia, the north end of the needle was successively drawn to the west at a maximum rate of $8^{\prime}$ or $10^{\prime}$ a year. From the meridian of the North Cape of Europe to that of $130^{\circ}$ east, it was's stccessively drawn to the east, while from thence to Hudson's Bay it was nearly stationary, or perhaps oscillated a little: in the southern hemisphere, from about the western part of Australia to Cape Horn, the movement was throughout to the east at the maximum rate of $7^{\prime}$ a year. There was thus a general uniformity of movement : in that hemisphere [dividing the globe into eastern and western hemispheres] which includes the Atlantic and Indian Oceans, the needle was constantly drawn more and more to the west ; in the hemisphere embracing the Pacific Ocean, more and more to the eact.

"So far then to the early part of the present century we can trace a harmonious movement of the needle over the whole globe, justifying the conclusions of our old philosophers; but in the year 1818 at London, and generally contemporaneous with that epoch throughout Europe and North Africa, the westerly progress of the north end of the needle ceased, and an easterly movement commenced; this continues to the present time, and with a yearly increasing rate. But in the South Atlantic during this period the westerly movement has never ceased; it is still going on, and in some parts with rapidity. Here, then, is a marked dislocation of the harmonious regularity embodied in Halley's and Hansteen's calculations and conceptions.

"The matured views of Sir Edward Sabine, to which I have drawn attention, seem to anticipate the difficulties attendant on this new and complex movement ; for, if I apprehend his meaning correctly, they imply that the poles of attraction which have a terrestrial source, i.e. the magnetic polse, are not subject to transiation. ${ }^{2}$

"The hypothesis, if further followed, is nevertheless beset with difficulties ; for we can scarcely conceive changes due to cosmical action to be otherwise than general in character, and to affect the whole globe. 'Thus, if the progressive translation of the induced or weaker system in Northern Asia - and presumably of that in the southern hemisphere-were the direct causes of the secular charges, we should anticipate uniformity in the general movements of the needle as manifested by its variation and dip over the earth's surface. But this is contrary to modern experience; for in some regions great activity of movement, both in the direction of pointing and in the inclination of the needle, is going on; in others there is comparative repose in both elements; while in another region the needle remains nearly constant in its direction, while its inclination sensibly varies from year to year. For example:--

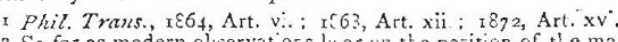

2 So far as modern olsservatiors bear on th e po:ition of ti.e magnetic poles, they indicate permanency rather than change of piace.
"A region of remarkable activity presents itself in the South Atlantic Ocean : a great part of the seaboard of South America extending to Cape Horn, and including St. Paul's Rocks, Ascension, St. Helena, and the Falkland Islands, with their adjacent seas, are embraced therein. In some parts of this area the westerly movement of the needle exceeds $7^{\prime}$ or $8^{\prime}$ a year, and has so progressed for nearly three centuries. On the American coast the dip of the south end of the needle decreases from $7 \cdot 5^{\prime}$ to $4^{\prime}$ yearly, while from the Cape of Good Hope to Ascension it increases from $5^{\prime}$ to $1 \mathrm{IO}^{\prime}$ yearly. We have here, within narrow limits, a noteworthy dislocation of the observed phenomena.

"Another region of activity, so far as is denoted by the changes of variation, extends over Europe, Western Asia, and North Africa. Here the needle, in opposition to the protracted westerly movement going on in the South Atlantic, commenced moving to the eastward in the early part of this century; it has a progressive rate which in some parts now amounts to 10 ' a year. The dip diminishes in this region seldom more than 3 a year.

"A region of activity, so far as the dip is concerned, but with little change in the variation, is to be found on the west coast of South America ; at Valparaiso, as at the Falkland Islands, the south dip decreases at the rate of $z^{\prime}$ yearly, but in sailing northward and reaching the ro!h degree of south latitude, this active movement appears to cease.

"But little activity in either element now exists over the habitable part of the North American continent or in the West Indies. Throughout China there is little change in the variation, but an increasing dip of $3^{\prime}$ or $4^{\prime}$, and thus a reverse movement to that going on in Europe.

"Over a great part of the Western Pacific Ocean, as also in Australia and New Zealand, there is so little change in the two elements that this may be termed a region of comparative repose.

"These are a few facts relating to secular changes going on in two magnetic elements within our own time; and what are the inferences to be drawn therefrom? They appear to me to lead to the conclusion that movements, certainly beyond our present conception, are going on in the interior of the earth; and that so far as the evidence presents itself, secular changes are due to these movements and not to external causes: we are thus led back to Halley's conception of an internal nucleus or inner globe, itself a magnet, rotating within the outer magnetised shell of the earth.

"We need not here pause to discuss the probability of this fanciful conception of the old philosopher, but proceed to examine how far the behaviour of another element, the intensity of the earth's magnetism, confirms the view that movements are going on in the interior of our globe. In common I believe with all those who have pursued the study of this element from the time when Sabine's original memoir to the British Association [1837] threw so much light on this special division of the subject, I had conceived that stability, within very limited conditions, was a distinctive condition of the earth's force; and that it was alone by watchful attention to the instruments of preci:ion devised for its determination that changes in short intervals of time, such as a generation, could be detected. 1 If we turn to the results obtained in this country through nearly half a century, it is possible that an increase of two or three hundredth. of the total force may be found. In Italy at the present time the annual decrease has been given by that active observer, the Rev. Father Perry, as ${ }^{\circ} 004$; so also on the North American continent, where, as we are told by the zealous magnetician, Schott, there is evidence of the force slightly increasing at Washington, of being stationary at 'Toronto, in Canada, and slightly decreasing at Key West, in the Gulf of Mexico. So far stability, within very small limits, obtains over a very large part of the northern hemisphere. If, however, we turn to the continent of South America and its adjacent seas (parts of which are regions of marked activity as denoted by changes in the variation and dip of the needle), we shall find a diminution of the intensity of the earth's force now going on in a remarkable degree; an examination of the recent observations made by the

$I$ The investigations of that able magnetician, Mr. Broun, lead him to consider that the earch's magnetic force increases and diminishes from day to day by nearly the same amount cver the whole globe. These increases to day by nearly the same amount cver the whole globe. These nacrease and diminutions have been traced to the action of the sun in stch a or multiples of twenty-six days-a pericd-attributable to the sua's ritation. 
Challenger's officers ${ }^{1}$ at Valparaiso and Monte Video, compared with those made by preceding observers, show that within half a century the whole force had respectively climinished one-sixth and one-seventh - at the Falkland Islands one-ninth. Farther north we find at Bahiz and Ascension Island, in the same period of time, an equally marked diminution of one-ninth of the force. This area of diminishing force has wide limits; it would appear to reach the equator and to aproach 'Tahiti on the west and St. Helena on the east ; at the Cape of Good Hope there is evidence of the force increasing.

"Such are the facts, and how are we to interpret them? Which. ever way we look at the subject of the earth's magnetism and its secular changes, we find marvellous complexity and mystery; lapse of time and increase of knowledge appear to have thrown us farther and farther back in the solution. The terella of Halley, the revolving poles of Hansteen, and the more recent hypotheses of the ablest men of the day, all fail to solve the mystery. We must not, however, be discouraged at these repulses in the great conflict for the advancement of human knowledge. The present century has been productive of keen explorers in the field of terrestrial magnetism; others emulous of fame are pressing rapidly from the rear, and knowing as we do that knowledge shall be increased, we may confidently anti. cipate the day when this, one of Nature's most formidable secrets, shall be revealed,"

\section{UNIVERSITY AND EDUCATIONAL \\ INTELLIGENCE}

At the annual meeting of the Convocation of the University of London on May I 4, a report from the annual committee was presented which recommended closer union and co-operation of the colleges and medical schools affiliated to the University with cach other and with the Senate, and also more clirect participation by the University in the work of higher education and in the encouragement of mature original work. The following resoIutions were carried by large majorities after an animated debate, in which Drs. Odling, Payne, Baxter, Pye-Smith, and Weymouth, and Messrs. Hutton, Carey Foster, R. N. Fowler, and Fitch, took part:- - I. That while Convocation recognises the advantages of examinations conducted by a body independent of the teachers of the candidates for degrees, it is expedient that the course of study purstied in those institutions should be brought into closer connection with the Senate. 2. That with this object it is desirable for the Senate to exercise its power uncier the present Charter of revising the list of affiliated $\mathrm{Col}$. leges, and from time to time of admitting to or excluding from this list according to the position taken by these Colleges at the University examinations for degrees, and on such other grounds as the Senate may in each case determine. 3. 'That it would be desirable that the educating bodies included in the revised list should be invited to communicate, by delegates or in writing, with the Senate, and that facilities should be afforded to such delegates of deliberating together and of communicating with the Senate, especially on the subject of examinations. 4. That it is desirable for the examiners of the University, either in faculties or collectively, to form a Board, one of whose functions would be to consider and report upon any subject connected with the examinations which they might deem of importance to the University. 5. That it is desirable that the University should take advantage of such opportunities as may present them. sclves of promoting, by the institution of University chairs, or otherwise, the cultivation of such higher or less usual branches of study as can be more conveniently or more efficiently taught by a central body. 6 . That it is desirable for the Senate to consider the importance of recognising independent research in the examinations for the higher degrees in such way as the senate may approve.

it M. Bardoux has sent to the French Chamber of Deputies a project for establishing in Algiers écoles préparatoires of science, letters, and law, in order to organise in the colony superior terching. The expenses are estimated at one-and-a.half million of francs. An école priparatoire of medicine was established eighteen years ago.

The late Prof. Wilhelm Piitz, well known through his excellent geographical and historical hand-books, has bequeathed the

I This cxterded and carefully made series are prepared for publication : we cannot too highly estimate this valuable contributic to magnet cal science. sum of I I 5,000 reichsmark $(5,750 l$.) to the University of Bonn, with the stipulation that it is to be employed for furthering the eaching of geography and history.

\section{SCIENTIFIC SERIALS}

Ancrican Fournal of Science and Arts, April. - In this number Prof. Hastings records observations which prove that the variation in dispersive power of glass, attending variation in temperature, is relatively enormously greater than that in the refractive power. This could hardly have before escaped notice, but for a singular relation in the co-efficients, in virtue of which probably, an achromatic combination for one temperature is good for all others within moderate limits. - Prof. Rowland has made a new determination of the absolute unit of electrical resistance, his method being to induce a current in a closed circuit by re versal of the main current. He finds the B.A. unit too great by about 88 per cent. A difference of nearly 3 per cent. between his result and that of Kohlrausch he endeavours to explain from a criticism of the latter's method, pointing out what he thinks its defects. - Prof. Langley differs from M. Janssen as to the ultimate form of the "grains" in the solar photosphere, regarding them as the ends of filaments (a simile he employs is that of a bird's-eye view of a field of grain acted on by wind), whilst $M$. Janssen thinks them literal spheres.-In the projection of microscope photographs, Prof. Draper increases the brilliancy of the result by removing the supporting stage of the slide further from the condenser so that a convergent beam of light may fall on the object.-Several papers in this number deal with points in American geology and physiography; the surface geology of South-West Pennsylvania, the driftless interior of North America, the ancient outlet of the Great Salt Lake, Lower Silurian fossils in Pennsylvanian limestone, intrusive nature of the triassic trapsheets of New Jersey, \&c. A tree-like fossil plant, Glypto dendron, lately found in the Upper Silurian rocks of Ohio is described by Prof. Claypole as (from its position) possessing a peculiar interest.

Annalen der Physik und Chemie, No. 3, 1878.-M. Röntgen here describes experiments which seem to invalidate results obtained by Wilhelmy in 1863 and I 864 regarding the condensa. tion of fluids on the surface of solid bodies. He finds the difference of the two surface tensions, caoutchonc-air and caoutchoncwater, to be about $8.0 \mathrm{mg}$. per millimetre, when both have attained their normal value (which does not occur immediately after contact). - It is shown by $\mathrm{M}$. Claes that for extremely dilute solutions of a substance with absorption-bands, the position of these bands may considerably vary, and a band is absoIutely characterised by that wave-length which belongs to it in solution in solvents that are without dispersion.-In a paper on quantitative spectrum analysis, $M$. Vierordt investigates the influence of narrowing of the entrance-slit on colour-tone and brightness; by adapting four movable plates to the slit he has been able accurately to fix the amount of error in his determinations of intensity of light with his spectral photometer, and show that throughout the spectrum they are very small, and may mostly be neglected. In every case, however, they can be fully corrected by arrangements he describes. $-M$. Lommel advances a theory of normal and anomalous dispersion, and M. Fröllich applies the principle of conservation of energy to the phenomena of cif. fraction. - The temperature-surface of water vapour is treated by M. Ritter.

\section{SOCIETIES AND ACADEMIES LONDON}

Royal Society, April 4.- "On the Determination of the Constants of the Cup Anemometer by Experiments with a Whirling Machine," by T. R. Robinson, D.D., F.R.S.

In his description of the cup anemometer (Trans. R. I. Academy, vol. xxii.), Dr. Robinson had inferred from experiments on a very limited scale with Robins whirling machine that the limiting ratio of the wind's velocity to that of the centres of the cups $=3$. Recent experiments by $M$. Dohrandt have shown that this number is too great. As some of the details of $M$. Dohrandt's experiments appeared objectionable, and as all the data necessary for determining the constants were not given, it seemerl desirable to repeat them. 